\title{
MicroRNA-488-3p is expressed highly in ethanol- induced cardiomyocytes and regulates mitochondrial function via target gene MFN1
}

Ye Liu (D 601924547@qq.com )

First Affiliated Hospital of Jinzhou Medical University

Bing Song

First Affiliated Hospital of Jinzhou Medical University

Keywords:

Posted Date: May 15th, 2020

DOl: https://doi.org/10.21203/rs.3.rs-27570/v1

License: (9) (i) This work is licensed under a Creative Commons Attribution 4.0 International License.

Read Full License 


\section{Abstract}

The authors have requested that this preprint be removed from Research Square. 